\title{
Engine of Innovation: Building the High Performance Catalog
}

\section{ABSTRACT}

Numerous studies have indicated that sophisticated web-based search engines have eclipsed the primary importance of the library catalog as the premier tool for researchers in higher education. We submit that the catalog remains central to the research process. Through a series of strategic enhancements, the University of North Carolina at Chapel Hill, in partnership with the other members of the Triangle Research Libraries Network (TRLN), has made the catalog a carrier of services in addition to bibliographic data, facilitating not simply discovery, but also delivery of the information researchers seek.

\section{INTRODUCTION}

In 2005, an OCLC research report documented what many librarians already knew - that the library webpage and catalog were no longer the first choice to begin a search for information. The report states,

The survey findings indicate that 84 percent of information searches begin with a search engine. Library Web sites were selected by just 1 percent of respondents as the source used to begin an information search. Very little variability in preference exists across geographic regions or U.S. age groups. Two percent of college students start their search at a library Web site. $^{1}$

In 2006 a report by Karen Calhoun, commissioned by the Library of Congress, asserted, "Today a large and growing number of students and scholars routinely bypass library catalogs in favor of other discovery tools... The catalog is in decline, its processes and structures are unsustainable, and change needs to be swift."2

Ithaka $\mathrm{S}+\mathrm{R}$ has conducted national faculty surveys triennially since 2000 . Summarizing the 20002006 surveys, Roger Schonfeld and Kevin Guthrie stated, "When the findings from 2006 are compared with those from 2000 and 2003, it becomes evident that faculty perceive themselves as becoming decreasingly dependent on the library for their research and teaching needs." ${ }^{3}$ Furthermore, it was clear that the "library as gateway to scholarly information" was viewed as decreasingly important. The 2009 survey continued the trend with even fewer faculty seeing the

Will Owen (owen@email.unc.edu) is Associate University Librarian for Technical Services and Systems and Sarah C. Michalak (smichala@email.unc.edu) is University Librarian and Associate Provost for University Libraries, University of North Carolina at Chapel Hill. 
gateway function as critical. These results occurred in a time when electronic resources were becoming increasingly important and large Google-like search engines were rapidly gaining in use. $^{4}$

These comments extend into the twenty-first century more than thirty years of concern about the utility of the library catalog. Through the first half of this decade new observations emerged about patron perceptions of catalog usability. Even after migration from the card to the online catalog was complete, the new tool represented primarily the traditionally cataloged holdings of a particular library. Providing direct access to resources was not part of the catalog's mission. Manuscripts, finding aids, historical photography, and other special collections were not included in the traditional catalog. Journal articles could only be discovered through abstracting and indexing services. As these discovery tools began their migration to electronic formats, the centrality of the library's bibliographic database was challenged.

The development of Google and other sophisticated web-based search engines further eclipsed the library's bibliographic database as the first and most important research tool. Yet we submit that the catalog database remains a necessary fixture, continuing to provide access to each library's particular holdings. While the catalog may never regain its pride of place as the starting point for all researchers, it still remains an indispensable tool for library users, even if it may be used only at a later stage in the research process.

At the University of North Carolina at Chapel Hill, we have continued to invest in enhancing the utility of the catalog as a valued tool for research. Librarians initially reasoned that researchers still want to find out what is available to them in their own campus library. Gradually they began to see completely new possibilities. To that end, we have committed to a program that enhances discovery and delivery through the catalog. While most libraries have built a wide range of discovery tools into their home pages-adding links to databases of electronic resources, article databases, and Google Scholar-we have continued to enhance both the content to be found in the primary local bibliographic database and the services available to students and researchers via the interface to the catalog.

In our local consortium, the Triangle Research Libraries Network (TRLN), librarians have deployed the search and faceting services of Endeca to enrich the discovery interfaces. We have gone beyond augmenting the catalog through the addition of MARCIVE records for government documents, by including Encoded Archival Description (EAD) finding aids and selected (and everexpanding) digital collections that are not easily discoverable through major search engines. We have similarly enhanced services related to the discovery and delivery of items listed in the bibliographic database, including not only common features like the ability to export citations in a variety of formats but also more extensive services such as document delivery, an auto-suggest feature that maximizes use of Library of Congress Subject Headings (LCSH), and the ability to submit cataloged items to be processed for reserve reading. 
Both students and faculty have embraced e-books, and in adding more than a million such titles to the UNC-Chapel Hill catalog we continue to blend discovery and delivery, but now on a very large scale. Coupling catalog records with a metadata service that provides book jackets, tables of contents, and content summaries, cataloging Geographic Information Systems (GIS) data sets, and adding live links to the finding aids for digitized archival and manuscript collections have further enhanced the blended discovery/delivery capacity of the catalog.

We have also leveraged the advantages of operating in a consortial environment by extending the discovery and delivery services among the members of TRLN to provide increased scope of discovery and shared processing of some classes of bibliographic records. TRLN comprises four institutions and content from all member libraries is discoverable in a combined catalog (http://search.trln.org). Printed material requested through this combined catalog is often delivered between TRLN libraries within twenty-four hours.

At UNC, our search logs show that use of the catalog increases as we add new capacity and content. These statistics demonstrate the catalog's continuing relevance as a research tool that adds value above and beyond conventional search engines and general web-based information resources. In this article we will describe the most important enhancements to our catalog, include data from search logs to demonstrate usage changes resulting from these enhancements, and comment on potential future developments.

\section{LITERATURE REVIEW}

An extensive literature discusses the past and future of online catalogs, and many of these materials themselves include detailed literature reviews. In fact, there are so many studies, reviews, and editorials, it becomes clear that although the online catalog may be in decline, it remains a subject of lively interest to librarians. Two important threads in this literature report on user-query studies and on other usability testing. Though there are many earlier studies, two relatively recent articles analyze search behavior and provide selective but helpful literature surveys. ${ }^{5}$

There are many efforts to define directions for the catalog that would make it more web-like, more Google-like, and thus more often chosen for search, discovery, and access by library patrons. These articles aim to define the characteristics of the ideal catalog. Charles Hildreth provides a benchmark for these efforts by dividing the history of the online catalog into three generations. From his projections of a third generation grew the "next generation catalog"-really the current ideal. He called for improvement of the second-generation catalog through an enhanced usersystem dialog, automatic correction of search-term spelling and format errors, automatic search aids, enriched subject metadata in the catalog record to improve search results, and the integration of periodical indexes in the catalog. As new technologies have made it possible to achieve these goals in new ways, much of what Hildreth envisioned has been accomplished. ${ }^{6}$ 
Second-generation catalogs, anchored firmly in integrated library systems, operated throughout most of the 1980s and the 1990s without significant improvement. By the mid-2000s the search for the "next-gen" catalog was in full swing, and there are numerous articles that articulate the components of an improved model. The catalog crossed a generational line for good when the North Carolina State University Libraries (NCSU) launched a new catalog search engine and interface with Endeca in January 2006. Three NCSU authors published a thorough article describing key catalog improvements. Their Endeca-enhanced catalog fulfilled the most important criteria for a "next-gen" catalog: improved search and retrieval through "relevance-ranked results, new browse capabilities, and improved subject access." ${ }^{7}$

Librarians gradually concluded that the catalog need not be written off but would benefit from being enhanced and aligned with search engine capabilities and other web-like characteristics. Catalogs should contain more information about titles, such as book jackets or reviews, than conventional bibliographic records offered. Catalog search should be understandable and easy to use. Additional relevant works should be presented to the user along with result sets. The experience should be interactive and participatory and provide access to a broad array of resources such as data and other nonbook content. 8

Karen Markey, one of the most prolific online catalog authors and analysts, writes, "Now that the era of mass digitization has begun, we have a second chance at redesigning the online library catalog, getting it right, coaxing back old users and attracting new ones." 9

Marshall Breeding predicted characteristics of the next-generation catalog. His list includes expanded scope of search, more modern interface techniques, such as a single point of entry, search result ranking, faceted navigation, and "did you mean ... ?" capacity, as well as an expanded search universe that includes the full text of journal articles and an array of digitized resources. ${ }^{10}$

A concept that is less represented in the literature is that of envisioning the catalog as a framework for service, although the idea of the catalog designed to ensure customer self-service has been raised. ${ }^{11}$ Michael J. Bennett has studied the effect of catalog enhancements on circulation and interlibrary loan. ${ }^{12}$ Service and the online catalog have a new meaning in Morgan's idea of "services against texts," supporting "use and understand" in addition to the traditional "find and get."13 Lorcan Dempsey commented on the catalog as an identifiable service and predicts new formulations for library services based on the network-level orientation of search and discovery. ${ }^{14}$ But the idea that the catalog has moved from a fixed, inward-focused tool to an engine for services-a locus to be invested with everything from unmediated circulation renewal and ordering delivery to the "did you mean" search aid—has yet to be addressed comprehensively in the literature.

\section{ENHANCING THE TRADITIONAL CATALOG}

One of the factors that complicates discussions of the continued relevance of the library catalog to research is the very imprecision of the term in common parlance, especially when the chief point 
of comparison to today's ILS-driven OPACs is Google or, more specifically, Google Scholar. From first-year writing assignments through advanced faculty research, many of the resources that our patrons seek are published in the periodical literature, and the library catalog, the one descended from the cabinets full of cards that occupied prominent real estate in our buildings, has never been an effective tool for identifying relevant periodical literature.

This situation has changed in recent years as products like Summon, from ProQuest, and EBSCO Discovery Service have introduced platforms that can accommodate electronic article indexing as well as MARC records for the types of materials—books, audio, and video-that have long been discovered through the OPAC. In the following discussion of "catalog" developments and enhancements, we focus initially not on these integrated solutions, but on the catalog as more traditionally defined. However, as electronic resources become an ever-greater percentage of library collections, we shall see a convergence of these two streams that will portend significant changes in the nature and utility of the catalog.

Much work has been done in the first decade of the twenty-first century to enhance discovery services and, as noted above, North Carolina State University's introduction of their Endeca-based search engine and interface was a significant game-changer. In the years following the introduction of the Endeca interface at NCSU, the Triangle Research Libraries Network invested in further development of features that enhanced the utility of the Endeca software itself.

Programmed enhancements to the interface provided additional services and functionality. In some cases, these enhancements were aimed at improving discovery. In others, they allowed researchers to make new and better use of the data that they found or made it easier to obtain the documents that they discovered.

\section{Faceting and Limiting Retrieval Results}

Perhaps the most immediately striking innovation in the Endeca interface was the introduction of facets. The use of faceted browsing allowed users to parse the bibliographic record in new ways (and more ways) than had preceding catalogs. There were several fundamentally important ways faceting enhanced search and discovery.

The first of these was the formal recognition that keyword searching was the user's default means of interacting with the catalog's data. NCSU's initial implementation allowed for searches using several indexes, including authors, titles, and subject headings, and this functionality remains in place to the present day. However, by default, searches returned records containing the search terms "anywhere" in the record. This behavior was more in line with user expectations in an information ecosystem dominated by Google's single search box.

The second was the significantly different manner in which multiple limits could be placed on an initial result set from such a keyword search. The concept of limiting was not a new one: certain facets worked in a manner consistent with traditional limits in prior search interfaces, allowing users to screen results by language, or date of publication, for example. 
It was the ease and transparency with which multiple limits could be applied through faceting that was revolutionary. A user who entered the keyword "java" in the search box was quickly able to discriminate between the programming language and the Indonesian island. This could be achieved in multiple ways: by choosing between subjects (for example, "application software" vs. "history") or clearly labeled LC classification categories ("Q - Science" vs. "D - History"). These limits, or facets, could be toggled on and off, independently and iteratively.

The third and highly significant difference resulted from how Library of Congress Subject Headings (LCSH) were parsed and indexed in the system. By making LCSH subdivisions independent elements of the subject-heading index in a keyword search, the Endeca implementation unlocked a trove of metadata that had been painstakingly curated by catalogers for nearly a century. The user no longer needed to be familiar with the formal structure of subject headings; if the keywords appeared anywhere in the string, the subdivisions in which they were contained could be surfaced and used as facets to sharpen the focus of the search. This was revolutionary.

\section{Utilizing the Power of New Indexing Structures}

The liberation of bibliographic data from the structure of MARC record indexes presaged yet another far-reaching alteration in the content of library catalogs. To this day, most commercial integrated library systems depend on MARC as the fundamental record structure. In NCSU's implementation, the multiple indexes built from that metadata created a new framework for information.

This change made possible the integration of non-MARC data with MARC data, allowing, for example, Dublin Core (DC) records to be incorporated into the universe of metadata to be indexed, searched, and retrieved. There was no need to crosswalk DC to MARC: it sufficed to simply assign the DC elements to the appropriate Endeca indexes. With this capacity to integrate rich collections of locally described digital resources, the scope of the traditional catalog was enlarged.

\section{Expanding Scopes and Banishing Silos}

At UNC-Chapel Hill, we began this process of augmentation with selected collections of digital objects. These collections were housed in a CONTENTdm repository we had been building for several years at the time of the Library's introduction of the Endeca interface. Image files, which had not been accessible through traditional catalogs, were among the first to be added. For example, we had been given a large collection of illustrated postcards featuring scenes of North Carolina cities and towns. These postcards had been digitized and metadata describing the image and the town had been recorded. Other collections of digitized historical photographs were also selected for inclusion in the catalog. These historical resources proved to be a boon to faculty teaching local history courses and, interestingly, to students working on digital projects for their classes. As class assignments came to include activities like creating maps enhanced by the 
addition of digital photographs or digitized newspaper clippings, the easy discovery of these formerly hidden collections enriched students' learning experience.

Other special collection materials had been represented in the traditional catalog in somewhat limited fashion. The most common examples were manuscripts collections. The processing of these collections had always resulted in the creation of finding aids, produced since the 1930s using index cards and typewriters. During the last years of the twentieth century, archivists began migrating many of these finding aids to the web using the EAD format, presenting them as simple HTML pages. These finding aids were accessible through the catalog by means of generalized MARC records that described the collections at a superficial level. However, once we attained the ability to integrate the contents of the finding aids themselves into the indexes underlying the new interface, this much richer trove of keyword-searchable data vastly increased the discoverability and use of these collections.

During this period, the Library also undertook systematic digitization of many of these manuscript collections. Whenever staff received a request for duplication of an item from a manuscript collection (formerly photocopies, but by then primarily digital copies), we digitized the entire folder in which that item was housed. We developed standards for naming these digital surrogates that associated the individual image with the finding aid. It then became a simple matter, involving the addition of a short JavaScript string to the head of the online finding aid, to dynamically link the digital objects to the finding aid itself.

Other library collections likewise benefited from the new indexing structures. Some uncataloged materials traditionally had minimal bibliographic control provided by inventories that were built at the time of accession in desktop database applications; funding constraints meant that full cataloging of these materials (often rare books) remained elusive. The ability to take the data that we had and blend it into the catalog enhanced the discovery of these collections as well.

We also have an extensive collection of video resources, including commercial and educational films. The conventions for cataloging these materials, held over from the days of catalog cards, often did not match user expectations for search and discovery. There were limits to the number of added entries that catalogers would make for directors, actors, and others associated with a film. Many records lacked the kind of genre descriptors that undergraduates were likely to use when seeking a film for an evening's entertainment. To compensate for these limitations, staff who managed the collection had again developed local database applications that allowed for the inclusion of more extensive metadata and for categories such as country of origin or folksonomic genres that patrons frequently indicated were desirable access points. Once again, the new indexing structures allowed us to incorporate this rich set of metadata into what looked like the traditional catalog.

Each of the instances described above represents what we commonly call the destruction of silos. Information about library collections that had been scattered in numerous locations-and not all of them online-was integrated into a single point of discovery. It was our hope and intention that 
such integration would drive more users to the catalog as a discovery tool for the library's diverse collections and not simply for the traditional monographic and serials collections that had been served by MARC cataloging. Usage logs indicate that the average number of searches conducted in the catalog rose from approximately 13,000 per day in 2009 to around 19,000 per day in 2013. It is impossible to tell with any certainty whether there was heavier use of the catalog simply because increasingly varied resources came to be represented in it, but we firmly believe that the experience of users who search for material in our catalog has become much richer as a result of these changes to its structure and content.

\section{Cooperation Encouraging Creativity}

Another way we were able to harness the power of Endeca's indexing scheme involved the shared loading of bibliographic records for electronic resources to which multiple TRLN libraries provided access. TRLN's Endeca indexes are built from the records of each member. Each institution has a "pipeline" that feeds metadata into the combined TRLN index. Duplicate records are rolled up into a single display via OCLC control numbers whenever possible, and the bibliographic record is annotated with holdings statements for the appropriate libraries.

We quickly realized that where any of the four institutions shared electronic access to materials, it was redundant to load copies of each record into the local databases of each institution. ${ }^{15}$ Instead, one institution could take responsibility for a set of records representing shared resources. Examples of such material include electronic government documents with records provided by the MARCIVE Documents Without Shelves program, large sets like Early English Books Online, and PBS videos streamed by the statewide services of NC LIVE.

In practice, one institution takes responsibility for loading, editing, and performing authority control on a given set of records. (For example, UNC, as the regional depository, manages the Documents Without Shelves record set.) These records are loaded with a special flag indicating that they are part of the shared records program. This flag generates a holdings statement that reflects the availability of the electronic item at each institution. The individual holdings statements contain the institution-specific proxy server information to enable and expedite access.

In addition to this distributed model of record loading and maintenance, we were able to leverage OAI-PMH feeds to add selected resources to the SearchTRLN database. All four institutions have access to the data made available by the Inter-university Consortium for Political and Social Research (ICPSR). As we do not license these resources or maintain them locally, and as records provided by ICPSR can change over time, we developed a mechanism to harvest the metadata and push it through a pipeline directly into the SearchTRLN indexes. None of the member libraries' local databases house this metadata, but the records are made available to all nonetheless.

While we were engaged in implementing these enhancements, additional sources of potential enrichment of the catalog were appearing. In particular, vendors began providing indexing services for the vast quantities of electronic resources contained in aggregator databases. 
Additionally, they made it possible for patrons to move seamlessly from the catalog to those electronic resources via OpenURL technologies. Indeed, services like ProQuest's Summon or EBSCO's Discovery Service might be taken as another step toward challenging the catalog's primacy as a discovery tool as they offered the prospect of making local catalog records just a fraction of a much larger universe of bibliographic information available in a single, keywordsearchable database.

It remains to be seen, therefore, whether continuing to load many kinds of MARC records into the local database is an effective aid to discovery even with the multiple delimiting capabilities that Endeca provides. What is certain, however, is that our approach to indexing resources of any kind has undergone a radical transformation over the past few years-a transformation that goes beyond the introduction of any of the particular changes we have discussed so far.

\section{Promoting a Culture of Innovation}

One important way Endeca has changed our libraries is that a culture of constant innovation has become the norm, rather than the exception, for our catalog interface and content. Once we were no longer subject to the customary cycle of submitting enhancement requests to an integrated library system vendor, hoping that fellow customers shared similar desires, and waiting for a response and, if we were lucky, implementation, we were able to take control of our aspirations. We had the future of the interface to our collections in our own hands, and within a few years of the introduction of Endeca by NCSU, we were routinely adding new features to enhance its functionality.

One of the first of these enhancements was the addition of a "type-ahead" or "auto-suggest" option. ${ }^{16}$ Inspired by Google's autocomplete feature, this service suggests phrases that might match the keywords a patron is typing into the search box. Ben Pennell, one of the chief programmers working on Endeca enhancement at UNC-Chapel Hill, built a Solr index from the ILS author, title, and subject indexes and from a log of recent searches. As a patron typed, a dropdown box appeared below the search box. The drop-down contained matching terms extracted from the Solr index in a matter of seconds or less. For example, typing the letters "bein" into the box produced a list including "Being John Malkovich," "nature-effects of human beings on," "human beings," and "Bein, Alex, 1903-1988." The italicized letters in these examples are highlighted in a different color in the drop-down display. In the case of terms drawn directly from an index, the index name appears, also highlighted, on the right side of the box. For example, the second and third terms in the examples above are tagged with the term "subject." The last example is an "author."

In allowing for the textual mining of LCSH, the initial implementation of faceting in the Endeca catalog surfaced those headings for the patron by uniting keyword and controlled vocabularies in an unprecedented manner. There was a remarkable and almost immediate increase in the number of authority index searches entered into the system. At the end of the fall semester prior to the implementation of the auto-suggest feature, an average of around 1,400 subject searches were 
done in a week. Approximately one month into the spring semester, that average had risen to around 4,000 subject searches per week. Use of the author and title indexes also rose, although not quite as dramatically. In the perpetual tug-of-war between precision and recall, the balance had decidedly shifted.

Another service that we provide, which is especially popular with students, is the ability to produce citations formatted in one of several commonly used bibliographic styles, including APA, MLA, and Chicago (both author-date and note-and-bibliography formats). This functionality, first introduced by NCSU and then jointly developed with UNC over the years that followed, works in two ways. If a patron finds a monographic title in the catalog, simply clicking on a link labeled "Cite" produces a properly formatted citation that can then be copied and pasted into a document. The underlying technology also powers a "Citation Builder" function by which a patron can enter basic bibliographic information for a book, a chapter or essay, a newspaper or journal article, or a website into a form, click the "submit" button, and receive a citation in the desired format.

An additional example of innovation that falls somewhat outside the scope of the changes discussed above was the development of a system that allowed for the mapping of simplified Chinese characters to their traditional counterparts. Searching in non-Roman character sets has always offered a host of challenges to library catalog users. The TRLN Libraries have embraced the potential of Endeca to reduce some of these challenges, particularly for Chinese, through the development of better keyword searching strategies and the automatic translation of simplified to traditional characters.

Since we had complete control over the Endeca interface, it proved relatively simple to integrate document delivery services directly into the functionality of the catalog. Rather than simply emailing a bibliographic citation or a call number to themselves, patrons could request the delivery of library materials directly to their campus addresses. Once we had implemented this feature, we quickly moved to amplify its power. Many catalogs offer a "shopping cart" service that allows patrons to compile lists of titles. One variation on this concept that we believe is unique to our library is the ability for a professor to compile such a list of materials held by the libraries on campus and submit that list directly to the reserve reading department, where the books are pulled from the shelves and placed on course-reserve lists without the professor needing to visit any particular library branch. These new features, in combination with other service enhancements such as the delivery of physical documents to campus addresses from our oncampus libraries and our remote storage facility, have increased the usefulness of the catalog as well as our users' satisfaction with the Library. We believe that these changes have contributed to the ongoing vitality of the catalog and to its continued importance to our community.

In December 2012, the Libraries adopted ProQuest's Summon to provide enhanced access to article literature and electronic resources more generally. At the start of the following fall semester, the Libraries instituted another major change to our discovery and delivery services through a combined single-search box on our home page. This has fundamentally altered how 
patrons interact with our catalog and its associated resources. First, because we are now searching both the catalog and the Summon index, the type-ahead feature that we had deployed to suggest index terms from our local database to users as they entered search strings no longer functions as an authority index search. We have returned to querying both databases through a simple keyword search.

Second, in our implementation of the single search interface we have chosen to present the results from our local database and the retrievals from Summon in two, side-by-side columns. This has the advantage of bringing article literature and other resources indexed by Summon directly to the patron's attention. As a result, more patrons interact directly with articles, as well as with books in major digital repositories like Google Books and HathiTrust. This change has undoubtedly led patrons to make less in-depth use of the local catalog database, although it preserves much of the added functionality in terms of discovering our own digital collections as well as those resources whose cataloging we share with our TRLN partners. We believe that the ease of access to the resources indexed by Summon complements the enhancements we have made to our local catalog.

\section{CONCLUSION AND FURTHER DIRECTIONS}

One might argue that the integration of electronic resources into the "catalog" actually shifts the paradigm more significantly than any previous enhancements. As the literature review indicates, much of the conversation about enriching library catalogs has centered on improving the means by which search and discovery are conducted. The reasonably direct linking to full text that is now possible has once again radically shifted that conversation, for the catalog has come to be seen not simply as a discovery platform based on metadata but as an integrated system for delivering the essential information resources for which users are searching.

Once the catalog is understood to be a locus for delivering content in addition to discovering it, the local information ecosystem can be fundamentally altered. At UNC-Chapel Hill we have engaged in a process whereby the catalog, central to the library's web presence (given the prominence of the single search box on the home page), has become a hub from which many other services are delivered. The most obvious of these, perhaps, is a system for the delivery of physical documents that is analogous to the ability to retrieve the full text of electronic documents. If an information source is discovered that exists in the library only in physical form, enhancements to the display of the catalog record facilitate the receipt by the user of the print book or a scanned copy of an article from a bound journal in the stacks.

In 2013, Ithaka S+R conducted a local UNC Faculty Survey. The survey posed three questions related to the catalog. In response to the question, "Typically when you are conducting academic research, which of these four starting points do you use to begin locating information for your research?," 41 percent chose "a specific electronic research resource/computer database." Nearly one-third (30 percent) chose "your online library catalog."17 
When asked, "When you try to locate a specific piece of secondary scholarly literature that you already know about but do not have in hand, how do you most often begin your process?," 41 percent chose the library's website or online catalog, and 40 percent chose "search on a specific scholarly database or search engine." In response to the question, "How important is it that the library ... serves as a starting point or 'gateway' for locating information for my research?," 78 percent answered extremely important.

On several questions, Ithaka provided the scores for an aggregation of UNC's peer libraries. For the first question (the starting point for locating information), 18 percent of national peers chose the online catalog compared to 30 percent at UNC. On the importance of the library as gateway, 61 percent of national peers answered very important compared to the 78 percent at UNC.

In 2014, the UNC Libraries were among a handful of academic research libraries that implemented a new Ithaka student survey. Though we don't have national benchmarks, we can compare our own student and faculty responses. Among graduate students, 31 percent chose the online catalog as the starting point for their research, similar to the faculty. ${ }^{18}$ Of the undergraduate students, 33 percent chose the Library's website, which provides access to the catalog through a single search box. ${ }^{19}$

A finding that approximately a third of students began their search on the UNC Library website was gratifying. OCLC's Perceptions of Libraries 2010 reported survey results regarding where people start their information searches. In 2005, 1 percent said they started on a library website; in 2010, not a single respondent indicated doing so. ${ }^{20}$

The gross disparity between the OCLC reports and the Ithaka surveys of our faculty and students requires some explanation. The Libraries at the University of North Carolina at Chapel Hill are proud of a long tradition of ardent and vocal support from the faculty, and we are not surprised to learn that students share their loyalty. For us, the recently completed Ithaka surveys point out directions for further investigation into our patrons' use of our catalog and why they feel it is so critical to their research.

Anecdotal reports indicate that one of the most highly valued services that the Libraries provide is delivery of physical materials to campus addresses. Some faculty admit with a certain degree of diffidence that our services have made it almost unnecessary to set foot in our buildings; that is a trend that has also been echoed in conversations with our peers. Yet the online presence of the Library and its collections continues to be of significant importance-perhaps precisely because it offers an effective gateway to a wide range of materials and services.

We believe that the radical redesign of the online public access catalog initiated by North Carolina State University in 2006 marked a sea change in interface design and discovery services for that venerable library service. Without a doubt, continued innovation has enhanced discovery. However, we have come to realize that discovery is only one function that the online catalog can and should serve today. Equally if not more important is the delivery of information to the 
patron's home or office. The integration of discovery and delivery is what sets the "next-gen" catalog apart from its predecessors, and we must strive to keep that orientation in mind, not only as we continue to enhance the catalog and its services, but as we ponder the role of the library as place in the coming years. Far from being in decline, the online catalog continues to be an "engine of innovation" (to borrow a phrase from Holden Thorp, former chancellor of UNC-Chapel Hill) and a source of new challenges for our libraries and our profession.

\section{REFERENCES}

1. Cathy De Rosa et al., Perceptions of Libraries and Information Resources: A Report to the OCLC Membership (Dublin, OH: OCLC Online Computer Library Center, 2005), 1-17, https://www.oclc.org/en-US/reports/2005perceptions.html.

2. Karen Calhoun, The Changing Nature of the Catalog and Its Integration with Other Discovery Tools, Final Report, Prepared for the Library of Congress (Ithaca, NY: K. Calhoun, 2006), 5, http://www.loc.gov/catdir/calhoun-report-final.pdf.

3. Roger C. Schonfeld and Kevin M. Guthrie, "The Changing Information Services Needs of Faculty," EDUCAUSE Review 42, no. 4 (July/August 2007): 8, http://www.educause.edu/ero/article/changing-information-services-needs-faculty.

4. Ross Housewright and Roger Schonfeld, Ithaka's 2006 Studies of Key Stakeholders in the Digital Transformation in Higher Education (New York: Ithaka S+R, 2008), 6, http://www.sr.ithaka.org/sites/default/files/reports/Ithakas_2006_Studies_Stakeholders_Di gital_Transformation_Higher_Education.pdf.

5. Xi Niu and Bradley M. Hemminger, "Beyond Text Querying and Ranking List: How People are Searching through Faceted Catalogs in Two Library Environments," Proceedings of the American Society for Information Science \& Technology 47, no. 1 (2010): 1-9, http://dx.doi.org/10.1002/meet.14504701294; and Cory Lown, Tito Sierra, and Josh Boyer, "How Users Search the Library from a Single Search Box," College \& Research Libraries 74, no. 3 (2013): 227-41, http://crl.acrl.org/content/74/3/227.full.pdf.

6. Charles R. Hildreth, "Beyond Boolean; Designing the Next Generation of Online Catalogs," Library Trends (Spring 1987): 647-67, http://hdl.handle.net/2142/7500.

7. Kristen Antelman, Emily Lynema, and Andrew K. Pace, "Toward a Twenty-First Century Library Catalog," Information Technology and Libraries 25, no. 3 (2006): 129, http://dx.doi.org/10.6017/ital.v25i3.3342.

8. Karen Coyle, "The Library Catalog: Some Possible Futures," Journal of Academic Librarianship 33, no. 3 (2007): 415-16, http://dx.doi.org/10.1016/j.acalib.2007.03.001.

9. Karen Markey, "The Online Library Catalog: Paradise Lost and Paradise Regained?" D-Lib Magazine 13, no. 1/2 (2007): 2, http://dx.doi.org/10.1045/January2007-markey. 
10. Marshall Breeding, "Next-Gen Library Catalogs," Library Technology Reports (July/August 2007): 10-13.

11. Jia Mi and Cathy Weng, "Revitalizing the Library OPAC: Interface, Searching, and Display Challenges," Information Technology and Libraries 27, no. 1 (2008): 17-18, http://dx.doi.org/10.6017/ital.v27i1.3259.

12. Michael J. Bennett, "OPAC Design Enhancements and Their Effects on Circulation and Resource Sharing within the Library Consortium Environment," Information Technology and Libraries 26, no. 1 (2007): 36-46, http://dx.doi.org/10.6017/ital.v26i1.3287.

13. Eric Lease Morgan, "Use and Understand; the Inclusion of Services against Texts in Library Catalogs and Discovery Systems," Library Hi Tech (2012): 35-59, http://dx.doi.org/10.1108/07378831211213201.

14. Lorcan Dempsey, "Thirteen Ways of Looking at Libraries, Discovery, and the Catalog: Scale, Workflow, Attention," Educause Review Online (December 10, 2012), http://www.educause.edu/ero/article/thirteen-ways-looking-libraries-discovery-andcatalog-scale-workflow-attention.

15. Charles Pennell, Natalie Sommerville, and Derek A. Rodriguez, "Shared Resources, Shared Records: Letting Go of Local Metadata Hosting within a Consortium Environment," Library Resources \& Technical Services 57, no. 4 (2013): 227-38, http://journals.ala.org/lrts/article/view/5586.

16. Benjamin Pennell and Jill Sexton, "Implementing a Real-Time Suggestion Service in a Library Discovery Layer," Code4Lib Journal 10 (2010), http://journal.code4lib.org/articles/3022.

17. Ithaka S+R, UNC Chapel Hill Faculty Survey: Report of Findings (unpublished report to the University of North Carolina at Chapel Hill, 2013), questions 20, 21, 33.

18. Ithaka S+R, UNC Chapel Hill Graduate Student Survey: Report of Findings (unpublished report to the University of North Carolina at Chapel Hill, 2014), 47.

19. Ithaka S+R, UNC Chapel Hill Undergraduate Student Survey: Report of Findings (unpublished report to the University of North Carolina at Chapel Hill, 2014), 39.

20. Cathy De Rosa et al., Perceptions of Libraries, 2010: Context and Community: A Report to the OCLC Membership (Dublin, OH: OCLC Online Computer Library Center, 2011), 32, http://oclc.org/content/dam/oclc/reports/2010perceptions/2010perceptions_all.pdf. 